\title{
EXPECTATIVAS PARENTAIS: O INTERNATO COMO CONTEXTO DE DESENVOLVIMENTO
}

\author{
PARENTAL EXPECTATIONS: THE BOARDING SCHOOL AS A \\ DEVELOPMENTAL CONTEXT
}

Demóstenes Neves da Silva*

Elaine Pedreira Rabinovich**

Silva DNd, Rabinovich EP. Expectativas parentais: o internato como contexto de desenvolvimento. Rev Bras Crescimento Desenvolv Hum. 2007; 17(3):60-71.

\begin{abstract}
Resumo: O estudo objetivou discutir os motivos e as expectativas dos pais ao conduzirem os filhos para uma educação no ensino regular da educação básica numa instituição interna e confessional. Como objetivos específicos, pretendeu traçar um perfil dos alunos e analisar a relação entre o papel da instituição e as expectativas parentais. Os instrumentos metodológicos foram questionários semi-estruturados aplicados a 20 pais que correspondiam ao total dos novos alunos do ano letivo e o diário de campo do pesquisador. São apresentados elementos de análise do internato agrupados como contexto de compensação, ideal de vida, substituto da família, fator de crescimento para os filhos e de desenvolvimento acadêmico. Conclui-se que o internato é procurado, na expectativa dos pais, como contexto privilegiado para a educação dos filhos em sua condição de fechamento e proteção e, paradoxalmente, como fator de crescimento e desenvolvimento.
\end{abstract}

Palavras-chave: Educação. Família. Internato. Ambiente.

\section{INTRODUÇÃO}

Este trabalho é parte de um estudo mais amplo ${ }^{3}$ que procurou compreender as trajetórias de jovens que viveram em um internato, localizado em Cachoeira, Bahia, denominado Instituto Adventista de Ensino do Nordeste (IAENE), com 2300 alunos, sendo aproximadamente 400 internos. A maioria dos internos são membros da denominação Adventista ou procedentes de famílias onde os pais ou pelo menos um deles é adventista. $\mathrm{O}$ presente estudo objetiva apresentar e analisar as expectativas paternas que motivaram a colocação dos filhos na instituição interna.

A educação em internatos é uma alternativa livre de escolha dos pais, sem impedimento legal, explorada pelo poder público e aberta à iniciativa privada. Historicamente, contudo, o internato tem sido considerado para atender populações de baixa renda e suprir deficiências familiares $^{1}$ (p. 17) e como uma das práticas sociais de modelagem da subjetividade ${ }^{2}$ (p. 19). No entanto, para Moraes et $\mathrm{al}^{3} \mathrm{o}$ colégio interno oferece elementos que proporcionam a formação do jovem num ambiente que pode conceder opor-

Este trabalho é parte da dissertação do Mestrado em Família na Sociedade Contemporânea da Universidade Católica do Salvador "Trajetórias no contexto de um internato: das expectativas familiares às experiências dos internos e egressos", Salvador (Bahia): março 2007, do primeiro autor orientado pelo segundo autor.

* Educador e teólogo, professor do Seminário Adventista Latino-Americano de Teologia, Cachoeira, Bahia, professor do programa de pós-graduação da Faculdade Adventista de Educação do Nordeste (FAENE) E-mail: demostenesneves@yahoo.com.br.

** Psicóloga, doutorado no Instituto de Psicologia da Universidade de São Paulo, professora do Mestrado em Família na Sociedade Contemporânea da UCSAL, membro fundador do Laboratório de Psicologia Sócio-Ambiental e Intervenção e membro do Centro de Estudos do Crescimento Desenvolvimento Humano. 
tunidades para o desenvolvimento de vínculos afetivos, amadurecimento pessoal por meio do convívio com pessoas diferentes e com situações que exigem resolução de problemas nas quais podem desenvolver os sentimentos de cooperação, "solidariedade, identidade grupal, intimidade e autonomia para administrar a própria vida" (p. 387).

Apesar do surgimento de redes de internatos ao redor do mundo ${ }^{4} \mathrm{e}$ do aparecimento nos últimos anos de novos internatos de grande porte no Brasil $1^{5}$, essas instituições e sua influência sobre os adolescentes como modalidade educacional ainda são temas pouco pesquisados ${ }^{3}$.

Pensar o internato como "instituição total", contexto que em parte é residência e em parte instituição formal ${ }^{6}$, regido por uma filosofia específica, com normas e controle próprios, e onde os estudantes permanecem por mais tempo sob o controle e disciplina normatizadora e normalizadora $^{7}$, é considerar as várias implicações para o desenvolvimento do educando interno.

Por se constituir, conforme Foucault ${ }^{7}$, um espaço onde o poder se exerce não apenas como força negativa, mas também produtiva, conduzindo à formação de um determinado tipo de indivíduo, surge o questionamento quanto à natureza e à extensão da influência do internato. Indaga-se como suas rotinas e forma específica de controle agiriam sobre os alunos.

Foucault $^{7}$ apresenta o poder disciplinar como uma técnica difusa presente em todas as formas de dominação, útil ou não, que são exercidas na sociedade ocidental a partir do século XVIII em todos os setores, incluindo a escola.

Por força da quantidade de indivíduos que ali residem, estudam e trabalham, o internato necessita normatizar e normalizar. Não aceitar as normas pode produzir sanções temidas pelos alunos internos. Entre os instrumentos utilizados nas instituições educacionais encontra-se o exame, que funciona como recurso de renovação constante de poder a favor do mestre na esco$\mathrm{la}^{7}$, e que garante a transmissão do saber e fornece o conhecimento útil sobre os alunos através de rituais contínuos de controle e avaliação.

Assim, a sanção normalizadora, adicionada à vigilância, combinada com o exame que é um procedimento específico da disciplina ${ }^{7}$, caracteriza o modo de agir das instituições internas. Para cada desvio, é prevista uma ação corretiva que obedece ao sistema gratificação-sanção que castiga e pune pelo rebaixamento e recompensa, pela promoção e qualificação ${ }^{7}$ (p. 149151).

Pesquisas têm mostrado que características como rotina, massificação, disciplina rígida tornam o ambiente insensível, desprovido de afeto e impessoal com prejuízos para "o indivíduo em vários aspectos especialmente no processo de formação da identidade e no desenvolvimento das relações sociais e afetivas" ${ }^{1}$ (p. 17).

Goffman ${ }^{6}$ conduziu estudos sobre as instituições fechadas por ele denominadas "instituições totais", "local de residência e trabalho onde um grande número de indivíduos com situação semelhante, separados da sociedade mais ampla por considerável período de tempo, leva uma vida fechada e formalmente administrada" (p. 11). O interesse sociológico da instituição total reside no fato de ser "um híbrido social, parcialmente comunidade residencial, parcialmente organização formal", além de se constituir na sociedade em "uma estufa para mudar pessoas" e "um experimento natural sobre o que se pode fazer ao eu" ${ }^{6}$ (p. 22).

Nas instituições totais, dentre as quais o internato se situa, a participação dos internos em muitas das atividades não é voluntária e a linha de autoridade se estende sobre o grupo mesmo quando deveria prevalecer a escolha pessoal. Além disso, ocorre o restrito contato com o mundo externo por parte dos internos ${ }^{6}$. Assim, em instituições para menores infratores, onde a separação é rigorosa, Antoneli ${ }^{1}$ ressalta a distância entre o mundo do interno e a vida civil, o que dificulta a reinserção do ex-interno na sociedade.

A ênfase de Goffman ${ }^{6}$ recai sobre a invasão da vida particular do indivíduo que é obrigado, muitas vezes, a conviver com quem não quer, não possuindo, normalmente, o direito de escolher seus companheiros de moradia, manter sob seu domínio objetos pessoais e exercer o direito de comer o que deseja. A perda de privacidade se manifesta porque o interno geralmente não pode escolher estar sozinho ou sem ser de algu- 
ma forma ouvido ou vigiado. Vivendo em grupos, o interno é obrigado a se "expor" em situações íntimas para os colegas sendo-lhe negada uma vida reservada, o que produz "angústia crônica quanto à desobediência às regras e suas conseqüências [...]" ${ }^{6}$ (p. 45).

Ainda, segundo Goffman ${ }^{6}$, em cada instituição total se pode "ver, em miniatura, o desenvolvimento de algo próximo de uma versão funcionalista da vida moral" (p. 80). Esta concepção levaria ao desenvolvimento de ações institucionais para harmonizar o comportamento dos internos à concepção moralista da instituição total, transformando o indivíduo à imagem e semelhança dos ideais institucionais.

\section{A Ecologia do Desenvolvimento}

A concepção ecológica de Bronfenbrenner ${ }^{8}$ fornece um instrumento apropriado para a compreensão dos significados do internato para os alunos e para as relações entre o internato e a vida fora dele devido aos efeitos da interação entre os vários níveis que compõem o ambiente. $\mathrm{O}$ ambiente é entendido como um sistema dinâmico no qual o indivíduo influencia e é influenciado por fatores presentes e ausentes, próximos e distantes. Porém, os eventos mais "imediatos e potentes" e que mais influenciam a pessoa em desenvolvimento são aqueles que "outras pessoas realizam com ela ou na sua presença"» (p. 7).

Mudanças na posição e/ou nos papéis da pessoa no ambiente podem ocorrer em qualquer nível e exigem acomodações mútuas entre o organismo e seu meio: são as transições ecológicas. Essas transições são o desenvolvimento em $\mathrm{si}^{8}$ (p.23).

O conceito de desenvolvimento ecológico de Bronfenbrenner ${ }^{8}$ é apresentado a partir de uma concepção de ambiente estruturado em quatro níveis superpostos e mutuamente articulados, no qual o indivíduo aparece simultaneamente como agente e paciente; produtor e produto em constante interação com o ambiente: o microssistema no qual se desenvolve uma relação diádica face a face; o mesossistema, um sistema de microssistemas, que inclui as inter-relações entre dois ou mais ambientes; o exossistema, ambiente que não envolve a pessoa como participante ativo; o macrossistema: consistência na forma e conteúdo nos níveis inferiores.

A relação diádica é vivenciada no internato em várias situações, especialmente nas relações do quarto, nas refeições diárias e na escola, assim como na interação das relações de namoro, nos bate-papos nas praças, nas práticas esportivas e nas atividades artísticas e sociais diversas, nas quais as amizades e relações ocorrem e se tornam duradouras, pelo menos durante o período que se encontram na instituição.

A análise ecológica aparece como adequada a uma instituição na qual cada setor e departamento funciona de modo planejado, objetivando a formação dos alunos de acordo com uma filosofia própria. Assim, na tentativa de reprodução da sociedade, encontram-se: a moradia (os residenciais); a escola (em um prédio localizado dentro do internato); a igreja (também dentro do internato e cujas atividades são parte do programa educacional da instituição); as áreas de lazer, esporte e artes proporcionando uma harmonia conjuntural voltada para a educação confessional que contrasta com o ambiente externo.

Pode-se dizer que o internato aparece, por esse ângulo, como um "experimento transformador" que desafia "as formas de organização social, sistemas de crença e estilos de vida dominantes numa determinada cultura ou subcultura" ${ }^{8}$ (p. 32).

É nossa hipótese de que as trajetórias de vida dos jovens são influenciadas pela sua vivência no internato. Trajetória é aqui identificada, segundo a proposta de Kurt Lewin ${ }^{9}$, em termos de teoria de campo, no qual estão presentes valências positivas e negativas relacionadas à necessidades da pessoa. Inclui a atualização contínua de possibilidades para a pessoa em desenvolvimento, favorecidas, ou não, pelo ambiente, também denominado contexto de desenvolvimento.

Inicialmente, são as expectativas dos pais, e nem sempre a dos futuros internos, os fatores decisivos para a vinda e permanência no internato. Aquilo que esperam receber em troca pelo que estarão investindo na instituição em termos financeiros e emocional é o fator que, geralmente, decide o internamento do aluno da educação 
básica. Por outro lado, essa motivação inicial é parte fundamental das futuras trajetórias possíveis destes alunos durante o período de tempo do internato e em suas vidas após terem dele saído.

Face ao exposto acima, propusemos realizar um estudo enfocando os motivos pelos quais os pais escolheram o internato para educar os seus filhos dado que a porta de entrada é um ponto fundamental das trajetórias. O estudo objetivou discutir os motivos e as expectativas dos pais ao conduzirem os filhos para uma educação no ensino regular da educação básica numa instituição interna e confessional. Como objetivos específicos, pretendeu traçar um perfil dos alunos e analisar a relação entre o papel da instituição e sua vinculação às expectativas parentais.

\section{MÉTODO}

Foram aplicados questionários semi-estruturados a todos os novos candidatos ao internato, em um total de vinte familiares, por ocasião de sua inscrição no início do ano letivo. Os questionários poderiam ser preenchidos por um ou ambos os pais no momento da matrícula e solicitavam identificação pessoal, dados escolares e nove questões visando a obter informações sobre as razões para a escolha e o que esperavam do internato em relação aos filhos.

Como parte do trabalho de campo, foram realizadas entrevistas informais no campus com cinco dos pais, objetivando uma complementação das informações dos questionários. Estas entrevistas foram transcritas, tão logo possível, em um diário de campo.

Os dados sócio-familiares dos questionários foram tabelados e os demais dados foram analisados identificando-se os conceitos neles implicados, agrupando-os e organizando-os como categorias empíricas, conforme explicitado na discussão.

\section{RESULTADOS}

A maioria dos estudantes está acima de quinze anos $(80 \%)$, cur- sando a partir da oitava série, sendo do sexo masculino $(60 \%)$ e procedente de famílias adventistas ou com um dos pais adventista, o próprio interno sendo da religião (Tabela I). São oriundos de escola particular $(70 \%)$, tendo sido aprovados no ano anterior ( $85 \%)$. Vindos da região norte e nordeste $(95 \%)$, conheceram o internato através da igreja, amigos e parentes. Também a maioria dos alunos decidiu por si mesma, ou em combinação com os pais, ir para o internato.

\begin{tabular}{|lc|}
\hline \multicolumn{2}{|l|}{ Tabela I - Religião da família e dos novos internos } \\
\hline Caracterização & Quantidade \\
\hline Família/aluno adventistas & 13 \\
\hline Mãe adventista/pai católico & 04 \\
\hline Família/aluno católicos & 03 \\
\hline Total & 20 \\
\hline
\end{tabular}

As razões para a escolha do internato foram classificadas em relação a: (1) expectativas dos pais quanto a espaços/serviços e (2) a estar separado da família.

1) Expectativas dos pais em relação aos filhos - espaços/serviços

O principal motivo alegado para a escolha do internato foi de natureza religiosa: nove pais apontaram como motivo principal a identificação religiosa: fé, igreja, filosofia; outros sete indicaram a busca por resultados acadêmicos: qualidade e condições de ensino; a terceira razão mencionada foi por ser um lugar mais seguro (02); $\mathrm{e}$, finalmente, em condições iguais estão: ter conseguido bolsa (01) e a escola ser perto de casa (01). (Tabela II)

\begin{tabular}{|lc|}
\hline \multicolumn{2}{|l|}{ Tabela II - Expectativas dos pais em relação aos filhos: espaços/serviços } \\
\hline Expectativas & Ocorrências \\
\hline $\begin{array}{l}\text { Religião, mesma fé, mesma igreja (adventista), } \\
\text { filosofia cristã, apoio espiritual. }\end{array}$ & 09 \\
\hline $\begin{array}{l}\text { Resultados acadêmicos, qualidade e condições } \\
\text { de ensino, estudar e aprender mais. }\end{array}$ & 07 \\
\hline Lugar mais seguro. & 02 \\
\hline Bolsa. & 01 \\
\hline Proximidade de casa. & 01 \\
\hline Total & 20 \\
\hline
\end{tabular}


O modelo bioecológico de Bronfenbrenner e Morris ${ }^{10}$ permite traçar uma relação entre os motivos acima apontados pelos pais e os vários níveis ecológicos. O macrossistema ao qual estão ligados os valores, crenças e religião adventista seria o primeiro deles. Os aspectos ligados ao ambiente, enquanto espaço imediato, onde o aluno estabelece relações com pessoas, objetos e símbolos propiciariam, na expectativa dos pais, melhor aproveitamento escolar, favorecido pelas características especiais do internato enquanto um microssistema formado por um conjunto de microssistemas integrados. Esses microssistemas integrados (escola, trabalho, praça, quadra, restaurante, etc.), dentro do próprio internato, parecem atuar de modo integrado nos discursos e estratégias religiosas e acadêmicas e, uma vez que são freqüentados pelo estudante, comporiam o mesossistema ideal, para os pais.

Quanto à segunda justificativa apresentada pelos pais para a escolha do internato, a qualidade e condições de ensino, estudar mais e preparo para o vestibular, estariam ligados a processos proximais planejados, regulares, progressivamente mais complexos, recíprocos e estimulantes na teoria e prática ${ }^{10}$ providos pelo internato. A disciplina e o regime interno, a segurança oferecida, as rotinas e o tempo que o estudante deve dedicar aos estudos são uma referência ao cronossistema da instituição, identificado na regularidade, periodicidade e duração das relações na escola, criando condições que levariam o aluno a esforçar-se mais nos estudos.

Finalmente, a escolha do internato está também relacionada à situação financeira, distância entre a residência e a escola e dificuldades para educar os filhos evidenciando aspectos do exossistema do estudante.

\section{2) Expectativas dos pais em relação aos fi-} lhos: estar separados da família

Estar no internato, separado dos pais, contribuiria para o desenvolvimento porque: ajuda o interno a: amadurecer (04); ser responsável (04); ser independente (04); obter autoconfiança e aprender que é capaz (02); aprender desprendimento (01); aprender a se relacionar (01); aprender a ter iniciativa (01). (Tabela III).

\begin{tabular}{|lc|}
\hline \multicolumn{2}{|c|}{$\begin{array}{c}\text { Tabela III - Expectativas dos pais em relação aos filhos - estar separado da } \\
\text { família }\end{array}$} \\
\hline Expectativas & Ocorrências \\
\hline Saber dar mais valor aos pais, às coisas. & 05 \\
\hline Ser responsável. & 04 \\
\hline Ser independente e obter autoconfiança. & 04 \\
\hline Amadurecimento. & 04 \\
\hline Saber que é capaz. & 02 \\
\hline Aprender a ter iniciativa. & 01 \\
\hline Aprender desprendimento. & 01 \\
\hline Aprender a se relacionar. & 01 \\
\hline TOTAL & 22 \\
\hline
\end{tabular}

Algumas referências (05) estão diretamente ligadas a "aprender" a dar valor, o que pode ser entendido como uma aspiração paterna em relação aos filhos ou como uma indicação de que o internato estaria sendo usado como um tipo de medida punitiva: se não aprenderam em casa, agora deverão aprender no internato.

Para os pais, a separação dos filhos estaria ligada a mudanças desejáveis nas atitudes e valores dos estudantes, como resultado do deslocamento do microssistema familiar para o da instituição. Aparentemente, os pais reconhecem sua dificuldade, ou incapacidade, para levar os filhos a desenvolverem as desejadas qualidades mencionadas acima, acreditando que o internato, como novo contexto e com novas relações, poderia fazer isso por eles e propiciar o aparecimento dessas competências.

\section{DISCUSSÃO}

As respostas ao questionário indicaram motivos relacionados a interesses religiosos, educacionais e psicológicos que seriam alcançados ou favorecidos pela experiência no internato. Pode-se inferir que a família percebe a necessidade de ajuda na tarefa de educar, e que esta seria conseguida no sistema de internato em lugar de outras alternativas disponíveis.

A seguir, apresentaremos a discussão or- 
ganizada em torno de categorias empíricas de análise que, embora apresentadas separadamente, encontram-se inter-relacionadas.

\section{O internato como "ideal de vida"}

As famílias investem no contexto interno e no que ele pode oferecer enquanto lugar ideal para a educação dos filhos. Mesmo considerando a oferta escolar adventista e de outras confissões religiosas nas suas cidades de origem, houve famílias que optaram pelo sistema de internato para os filhos. Consequentemente, a escolha considerou mais do que o fato de a escola possuir filosofia adventista. A escolha dos pais parece estar ligada à expectativa do que o modelo educacional em regime interno, associado à filosofia religiosa, pode oferecer. $\mathrm{O}$ internato oferece algo mais do ponto de vista educacional, o que, na visão da família, compõe esse "todo" que pode contribuir positivamente para a educação desejada. Essa preocupação com a proposta do "ambiente" ideal aparece nos depoimentos abaixo:

\section{ligião.”}

"Ambiente onde maioria é da mesma re-

"Minha maior preocupação é a má influência que um colégio que

não seja cristão possa causar em minha filha."

Assim, a escolha da maioria dos pais concorda com Neufeld ${ }^{11}$ ao declarar, como finalidade da escola adventista, a de oferecer uma "atmosfera" onde o estilo de vida religiosa "será, aos olhos da maioria dos estudantes, o padrão ideal e aceito de viver"' (p. 418). A concretização mais próxima dessa declaração pode ser observada na vida do campus, pois, possivelmente, em nenhuma outra situação, a filosofia adventista poderia ser levada mais próxima do seu ideal prático do que no contex to do internato.

Segundo os depoimentos dos pais adventistas, o ideal de educação, de acordo com a filosofia cristã, é difícil de ser levado a efeito, o que os faria delegar esta tarefa ao internato, onde processos proximais, desenvolvidos com outras pessoas em novo contexto e tempo, fariam a di- ferença na educação dos filhos. As dificuldades para manter os filhos dentro da filosofia cristã podem ser identificadas no macrotempo, que abrange as mudanças sociais nas expectativas e eventos sociais dentro e através das gerações ${ }^{10}$. Assim, possivelmente, as mudanças irão gerar conflitos nas relações entre pais e filhos, que configura, muitas vezes, um choque de gerações e contestação da autoridade paterna, mais ainda pelo acesso a um volume e diversidade de informações cada vez maiores e, em sua maioria, diferentes e opostos à religião da família. O internato, enquanto instituição total ${ }^{6}$ e disciplinar ${ }^{7}$ isolaria e filtraria elementos discordantes de sua filosofia, tornando-se um espaço protegido, nas palavras de alguns pais, das "más influências" e "da confusão do mundo" e, embora reconhecendo que no internato há problemas, acreditam que, para os filhos, estar nele "ainda é melhor".

Os pais, em suas expectativas, não denotaram conferir ao internato, enquanto "instituição total", um caráter negativo ou desvantajoso. Para eles, o controle e o direcionamento do internato, uma vez em harmonia com os seus valores, constituem um contexto ideal para o desenvolvimento dos filhos.

\section{O internato como compensação}

Em decorrência do item anterior, a escolha do internato aparece como uma solução compensatória ante fragilidades percebidas pelos pais, como prevenir os filhos de perigos ante um mundo em transformação. Os depoimentos revelaram que o perigo das más influências é entendido como estando por toda parte: mudanças desconhecidas, até perigosas, são identificadas mesmo dentro da família, em um cônjuge não crente ou em problemas nas relações familiares, amigos, meios de comunicação e em "outras escolas". Torna-se necessária, assim, na visão dos pais, uma providência de compensação, talvez em uma tentativa de anulação dos perigos do mundo externo. O sonho de educação dos filhos apresentado pelos pais foi o de um lugar seguro e confiável, que não traísse os valores nos quais desejavam que os filhos fossem criados. 
A principal razão é a confiança que deposito na educação adventista que pode ser obtida, de uma forma mais completa, em uma instituição onde tudo contribui de forma positiva.

Em caso de filhos que estejam sob influências, ou influenciados por valores e atitudes contrárias, o internato é visto como um local transformador; o lugar onde as limitações das famílias para formar e transformar a identidade dos estudantes serão compensadas. Esta concepção remete-nos mais uma vez a Goffman ${ }^{6}$ e ao poder transformador da instituição total.

to:O internato daria segurança aos pais de que os filhos estariam sendo vigiados e não se desviariam para práticas diferentes da educação oferecida na família. Esta situação poderia estar revelando que a educação religiosa seria frágil e poderia ser superada por valores contrários àqueles professados pelos pais; assim, o internato poderia ser um contexto que compensaria esta fragilidade e, ao mesmo tempo, evitaria expor os filhos a provas no mundo externo, para as quais não estariam preparados.

\section{O internato como substituto da família}

As famílias que escolheram o internato evidenciaram estar vivendo alguma dificuldade, ainda que momentânea, para educar devidamente os filhos.

"Porque me sinto mais segura e irá cuidar igual ou melhor que eu (espero)".

O internato, ao receber o aluno, torna-se depositário de um tipo de tutela do interno, cabendo-lhe oferecer amparo e proteção. Os pais compartilham a educação dos filhos com o internato, desde que lhes seja garantido que a instituição manterá certos padrões e valores, próximos aos que família estava ou gostaria de estar fornecendo em casa, mas que, por alguma razão, considera mais vantajoso e seguro passar a responsabilidade, no caso, para o internato. Assim, embora o internato tenha sido estabelecido como alternativa educacional cristã para alunos que não dispunham dela próxima aos seus lares, parece adquirir uma nova missão na concepção dos pais: o internato se apresenta como um meio de os pais tentarem concretizar a tarefa educacional da família, para a qual, percebem-se incapazes, parcial ou temporariamente, de levar a efeito, especialmente nos momentos de crise.

Os depoimentos indicam uma expectativa do que a escola pode fazer ao cuidar dos alunos:

"Porque acredito que para ele será muito bom conviver com pessoas que compartilham dos mesmos princípios e irão amadurecer com responsabilidade e com um apoio espiritual ótimo."

"Porque meu filho passará a ter mais responsabilidade e a valorizar mais a família e também os estudos."

Algumas famílias pareceram se sentir impotentes quanto ao que fazer para educar os filhos. Isso ocorre porque prevalece, em muitos lares, o modelo de autoridade parental rígido, predominante até o século XIX, e que entra em conflito com a mentalidade democrática atual. Ainda neste sentido, os pais perdem cada vez mais o papel de iniciadores do saber e da capacidade de exercer autoridade. Assim, a presença de novos modelos de relações familiares, mais igualitárias, baseadas mais em desejos do que em regras $^{12}$ faz surgir a necessidade de procurar ajuda para lidar com reações inesperadas de contestação e acomodação dos filhos no processo de educar. Por outro lado, reportando-nos à sociedade de controle mencionada por Deleuze ${ }^{13}$, os pais percebem que a sociedade mais ampla funciona de modo diverso de suas famílias e do internato, daí buscarem na instituição algo que não conseguem em um mundo que não controlam. O internato, para os pais, aparece como um substituto da família em uma tarefa que parece impossível ou difícil de levar a cabo, uma vez que, na instituição, podem ser encontradas a autoridade e o controle que parecem perdidos.

Essa transferência de tarefas constitui um tipo de co-responsabilidade da escola, presente nas expectativas familiares, que abrange o desempenho acadêmico, além da religiosidade, e 
se estende ao desenvolvimento de qualidades importantes para a vida civil, como amadurecimento, responsabilidade, independência, relacionamento, autoconfiança e iniciativa. Tarefas de responsabilidade da família são transferidas para o internato, nos limites do acordo estabelecido com a instituição, que assume, em certa medida, o papel familiar de "lócus que encerra também uma força promotora de condutas" ${ }^{14}$ (p.303). São esperadas desse novo ambiente e separação do pais a promoção de mudanças nos filhos:

"A juventude hoje acha que os pais são cafonas, então se faz necessário que se afastem para sentirem o valor dos pais e o amor eterno que temos por eles."

Assim, as mudanças sociais decorrentes daquelas que afetam a intimidade ${ }^{15}$ alteraram o modelo de família estabelecendo um choque de gerações. Neste sentido, a autoridade sobre os filhos foi dividida com o poder público, o qual, através de legislação direcionada à criança e ao adolescente $^{16}$, regula as ações dos pais em relação aos filhos, levando a um maior compartilhamento das tarefas educativas e de socialização com agências públicas e privadas ${ }^{17}$. Este é o trabalho que as famílias parecem esperar do internato: uma extensão do seu espaço e atuação num compartilhamento maior do que outras agências se propõem a oferecer. Os depoimentos informam que os pais esperam que os filhos recebam cuidado, apoio, tenham segurança e educação religiosa equivalente ao do ninho familiar.

Para os pais, "fechamento" e "proteção" (no internato) aparecem como sinônimos. Estes aspectos são potencialmente antagônicos a crescimento, independência; porém, embora fechados e protegidos, os pais esperam que os filhos amadureçam e aprendam a ser independentes. Assim, o internato surge na expectativa familiar como um lugar de proteção em virtude de sua característica de "instituição total", onde a vida dos filhos vai ser controlada, disciplinada, sem o perigo à espreita que existe no mundo exterior. Embora um ambiente fechado, onde a vida é formalmente administrada, o internato é, paradoxalmente, ao mesmo tempo, procurado como lugar de crescimento.

Esse sentido de fechamento e proteção, no que diz respeito ao internato, parece estar relacionado com a natureza da instituição. Reportando-nos à concepção de Bronfenbrenner $^{8}$, o internato aparece como sistema desenvolvimental que procura ser completo em si mesmo. Primeiro, devido à singularidade da instituição que, funcionando como uma microssociedade, pretende filtrar e isolar todo elemento contrário à sua proposta filosófica e, no entanto, manter canais abertos e trânsito constante com novas idéias, mas sempre vigiando-as de perto para que não subvertam sua proposta filosófica. Para alcançar este objetivo, a instituição estabelece mecanismos de controle e novos padrões de normalidade intramuros que alcançam todos os detalhes da vida o: $:^{7}$. Assim, o internato continua em contato regulado e comedido com o mundo externo, tanto na quantidade e qualidade do que pode estar em seu espaço (coisas, informações, lazer, por exemplo) como na periodicidade para estar e sair dele (a cada semana, nos recessos programados ou nas férias letivas). Neste contexto, os estudantes possuem certa autonomia para sua agenda pessoal, com pouco ou nenhum controle dos pais; mas, ao mesmo tempo, encontram-se presos a novas regras, hierarquia, etc. A porta está aberta para pais e alunos, mas, ao mesmo tempo, fechada pelos termos do acordo com a instituição, normalmente estabelecido entre o internato e os responsáveis pelos internos. Estes dois elementos, fechamento e liberdade, misturam-se no contexto da instituição, propiciando sua descrição por parte de pais e alunos como um espaço aberto e ao mesmo tempo fechado, onde os estudantes estão presos e têm liberdade; onde são controlados, mas podem ser independentes.

O segundo aspecto quanto ao fechamento, proteção e liberdade no internato, ainda considerando o modelo bioecológico de desenvolvimento, parece ser unidade e suficiência: um tipo de microssistema que basta a si mesmo, uma vez que ele contém, no seu espaço intramuros, todo o conjunto de outros microssistemas nos quais o estudante necessitaria transitar para desenvolver-se. $\mathrm{O}$ internato tem um mesossistema pró- 
prio, e no seu sistema organizacional mais amplo, seu macrossistema. Suas atividades programadas, regras e rotinas, retratam uma tentativa de lidar com o tempo, controlando e regulando-o nas relações com pessoas, coisas e símbolos. Essa unidade tem como objetivo harmonizar os discursos e práticas de modo a convergir e aperfeiçoar os propósitos educacionais da instituição - o esforço máximo na direção da educação integral, pretendida através da natureza unificada e auto-suficiente do internato.

Finalmente, o paradoxo de se estar preso, mas ao mesmo tempo livre, tenderia a criar a situação de ser obrigado pelos pais e, simultaneamente, estar ali por escolha ou consentimento. Esta situação aparece em depoimentos de alunos que foram convencidos pelos pais a aceitarem o internato, com a condição de saírem se não gostassem. No entanto, uma vez na condição de internos, com estudos em andamento, amizades, namoro e a contínua insistência dos pais, a saída não parece tão fácil e, embora não deixem de mencionar as restrições das normas internas, ao mesmo tempo relatam gostar e querer permanecer, pois se não quisessem continuar, sairiam quando bem entendessem do internato. Esta deve ser uma das razões que ajudam o interno a permanecer no internato: a de que está fechado e é independente para conduzir sozinho a vida e para sair da instituição.

"Eles aprenderão a caminharem sozinhos e colocar a sua independência em prática com o desenvolver dos seus estudos."

Isto ajuda a compreender a expectativa dos pais de, colocando em um internato, permitir, ao mesmo tempo, que estejam "por si mesmos" numa situação contraditória de fechamento e desenvolvimento. Neste sentido, os pais desejam que os filhos mudem e sejam independentes, contanto que seja dentro de um contexto controlado - o internato escolar. Assim, dependendo dos processos nos quais esteve envolvido no contexto do internato, do tempo ativo naquele ambiente e das características pessoais do estudan$t^{8}{ }^{8}$ o internato, em sua natureza paradoxal, estaria para os pais como substituto no processo de educar os filhos, funcionando como contexto transformador e produtor de trajetórias para os internos.

\section{$O$ internato como fator de crescimento dos filhos}

Informações adicionais, obtidas na experiência de campo, confirmam as indicações dos questionários dos pais também no que diz respeito ao exercício de autoridade sobre os filhos. Além de segurança e cuidado do "ninho", as famílias esperam que o internato ensine os filhos a serem "independentes", "responsáveis" e que aprendam a como "se virar na vida" e "caminharem sozinhos".

No estudo de Antoneli ${ }^{1}$ o resultado de sucesso na vida civil, numa das instituições pesquisadas, esteve relacionada ao exercício da autoridade orientada para a escolarização formal e treinamento profissional por meio de uma administração rígida e distante, enquanto não foi observado esse sucesso na instituição que deu ênfase ao contato afetivo.

"Ela, acredito eu que irá amadurecer e aprender que ela é capaz, se quiser."

"Para desenvolver o aspecto da responsabilidade e outros mais."

"Amadurecimento, quando se está longe dos pais a organização aumenta."

"Aprimoramento do caráter do aluno, a independência com responsabilidade, aprender a fazer suas próprias escolhas."

Contudo, os depoimentos dos dirigentes e internos estabelecem que a permanência harmoniosa com o contexto da escola dependerá da aceitação do aluno de estar no internato. Caso isto não ocorra, o resultado é a evasão do estudante, solicitada ou provocada às vezes pelo próprio interno, através de atitudes indisciplinadas objetivando o desligamento da instituição.

No entanto, embora sejam esperadas dificuldades de ajustamento ao novo ambiente ecológico, a permanência do estudante dependerá da sua capacidade de adaptar-se à complexidade da instituição de modo competente. Segundo 
o modelo bioecológico, as características biopsicológicas e aquelas construídas na interação com o ambiente, são importantes para o desenvolvimento da pessoa ${ }^{18}$. Assim, o desenvolvimento do estudante no internato dependeria, segundo a abordagem bioecológica, das disposições para responder seletivamente ao ambiente físico e social, tendência para engajar-se em atividades cada vez mais complexas e capacidade para conceitualizar suas experiências. Caso o novo interno manifeste dificuldades para manter controle sobre o comportamento e as emoções, através de impulsividade, explosividade, apatia, desatenção, irresponsabilidade, insegurança e timidez excessiva, estabelece-se um quadro de sofrimento e de difícil permanência na instituição. Entre as características biopsicológicas que poderiam favorecer ou dificultar o desenvolvimento do estudante estariam dotes e deficiências, tanto de natureza física e de competências, adquiridas no curso de vida da pessoa, e atributos pessoais físicos e modos de ser e características demográficas como idade, gênero e etnia, que produziriam diferenças na direção e força dos processos proximais e seus efeitos no desenvolvimento $^{18}$.

Outro fator importante para o crescimento psicológico dos filhos é a disciplina. Esta, delegada ao internato, aponta para o desejo da família de compensar o esvaziamento da autoridade familiar, centralizada tradicionalmente na figura paterna. Desse modo, o microssistema familiar aparece como enfraquecido em algumas de suas funções tradicionais. Não é incomum, segundo informação dos dirigentes, que os familiares e responsáveis pelos internos, em caso de conduta reprovável pela instituição, reforcem a delegação de tomar medidas disciplinares de acordo com o critério da escola. Essa função paterna também foi freqüentemente mencionada pelos familiares, além dos dirigentes do internato. Os alunos também, durante os diálogos mantidos durante a pesquisa, referem-se à autoridade exercida pelo internato, como expectativa de que este modelo educacional ensine o aluno a obedecer normas e a amadurecer. Ex-internos que visitam o campus, e outros que trabalham na instituição, também identificam essa tarefa do internato como uma contribuição para suas vidas, o que corrobora a expectativa familiar.

Esse aspecto de ensinar responsabilidade no cumprimento de horários, de potencializar as capacidades, de submeter o corpo a renúncias, canalizando as energias para finalidades úteis, foi identificado por Foucault ${ }^{\sim 7}$ como característica da sociedade disciplinar.

\section{O internato como desenvolvimento acadêmico}

$\mathrm{O}$ aspecto acadêmico foi outra expectativa familiar quanto ao internato. Os horários regulares obrigatórios de estudo, acompanhados por monitores que também podem oferecer reforço nas disciplinas estudadas; a presença de salas de estudo com divisórias individualizadas; o acompanhamento dos boletins e ausências e até ocorrências disciplinares, por parte dos professores e preceptores; o contato contínuo entre os residenciais e o prédio escolar dentro do próprio campus; a proximidade física entre escola, moradia, biblioteca; a possibilidade de perda de privilégios, em caso de falta às aulas, e de prêmios, em caso de estar com tudo em dia; enfim, o próprio contexto, o acompanhamento institucional ou o exemplo dos colegas que já se encontram no internato, favorecem o foco nos estudos e tendem, de acordo com aqueles que acompanham a vida acadêmica dos internos, a melhorar o desempenho escolar.

Outro aspecto que favorece a vida acadêmica, nesta inserção contextual no internato, é o incentivo ao estudo em grupos nos quartos, em lugar de na sala de estudos. Esta se constitui uma prática regular, na qual é possível identificar elementos do modelo ecológico ${ }^{8}$ nos processos proximais que ocorrem na interação entre as pessoas, de forma regular, diariamente e durante todo o período de estudos no internato. De acordo com depoimentos de alunos e preceptores, nesta dinâmica, em geral, mesmo os internos que possuem resistência às tarefas escolares, tendem a passar da observação para o compartilhamento nos estudos e, em seguida, para a aquisição do hábito de estudar que resulta em melhores notas no boletim escolar.

"Porque aqui é melhor para se prepa- 
rar para uma faculdade e para o vestibular."

"Para que o mesmo [aluno] tenha mais tempo dedicado à escola."

"O mesmo tem interesse em terminar o curso para voltar para casa."

A escolha do internato pelas famílias insere o aluno num contexto que estimula a adoção e permanência de atividades ali desenvolvidas como estudar, entre outras. A influência dessa relação entre pares, com monitores e com o ambiente em geral, contribuiria para a aquisição de novos hábitos e performances acadêmicas. Além disso, favorece a adoção de novos valores, crenças ou a confirmação delas. Algumas dessas atividades tendem a prosseguir mesmo num momento posterior devido ao efeito positivo dos processos proximais no desenvolvimento da pessoa $^{8}$.

\section{CONCLUSÃO}

Podem ser traçadas três trajetórias principais e genéricas quanto à inserção no internato a partir das expectativas dos pais: os pais querem que o filho seja educado dentro da religião; os pais querem uma boa escolarização; os pais esperam o crescimento psicológico dos filhos.

A análise dos elementos das expectativas das famílias de origem para a escolha da instituição interna permitiu seu agrupamento como contexto de ideal de vida, compensação, substituto da família, fator de crescimento para os filhos e de desenvolvimento acadêmico.

$\mathrm{Na}$ busca de possíveis trajetórias para os estudantes, a partir do passado, pudemos detectar o ambiente das famílias de origem dos adolescentes, os locais em que viveram e as crenças, ideais, oportunidades e conflitos que contribuíram para as famílias enviarem seus filhos para a instituição interna; na direção do futuro, teremos de considerar as expectativas realizadas ou não que, na esperança e desejos paternos e objetivos dos estudantes, proporcionaram sustentação para a sua permanência no internato.

Família e internato podem ser vistas como instituições que mutuamente se apóiam frente às mudanças do mundo externo. O internato constitui um dos espaços intermediários entre o público e o privado com potenciais para o desenvolvimento dos estudantes - uma passagem, na qual novas e diferentes possibilidades se abrem e se fecham nas expectativas familiares e nas dos próprios estudantes.

\begin{abstract}
The present study aimed at discussing the reasons and expectations of parents when they deliver their children to be educated in a confessional boarding school. As specific goals, this study intended to outline the students' profile and to analyze the relationship between the institution's role and the parents' expectations. The methodological instruments were semistructured questionnaires administered to 20 parents, corresponding to the total amount of new students in that school year, and the researcher's field diary. Elements of analysis of the boarding school are presented, grouped according to context of compensation, ideal of life, family substitute, growth factor, and academic development. In the conclusion, it is shown that the boarding school is chosen because, according to the parents' expectations, that environment appears as a privileged context to educate their children in a closed and protected condition and, paradoxically, as a factor for growth and development.
\end{abstract}

Keywords: Education. Family. Boarding School. Environment.

\section{REFERENCIAS}

1. Antoneli RM. O Educandário e o Sítio Pau d'Alho: as instituições enquanto contextos de desenvolvimento para crianças e adolescentes [dissertação]. São Paulo: Faculdade de
Medicina de Ribeirão Preto da USP; 1997.

2. Benelli SJ. O internato escolar como instituição total: violência e subjetividade. Psicologia em Estudo 2002;7(2): 19-29.

3. Morais NA et al. Notas sobre a experiência de vida num internato: aspectos positivos e 
negativos para o desenvolvimento dos internos. Psicologia em Estudo 2004; 9(3): 37987.

4. BSA - Boarding School Association e o anúncio de abertura de novos internatos. Disponível em: 〈http://www.boarding.org.uk/>. Acesso em: 3 set. 2006.

5. Escola Adventista no Brasil. Disponível em: $<$ http://www.adventista.org.br/EA/default.asp. $>$ Acesso em: 19 jan. 2006.

6. Goffman E. Manicômios, prisões e conventos. São Paulo: Perspectiva; 2005.

7. Foucault M. Vigiar e punir: história da violência nas prisões. $28^{\mathrm{th}}$ ed. Petrópolis: Vozes; 2004.

8. Bronfenbrenner U. A ecologia do desenvolvimento humano: experimentos naturais e planejados. Porto Alegre: Artes Médicas; 1996.

9. Lewin GW. Problemas de dinâmica de grupo. $3^{\text {rd }}$ ed. São Paulo: Cultrix; 1978.

10. Bronfenbrenner $\mathrm{U}$, Morris P. The ecology of developmental processes. In: Damon W, Lerner RM, organizadores. Handbook of child psychology: Theoretical models of human development. Vol 1, $5^{\text {th }}$ ed. New York: J. Wiley \& Sons ; 1998. p. 993-1027.

11. Neufeld DF et al, editores. Seventh-day Adventist Encyclopedia. Washington, D. C.: Review and Herald Publishing Association;
1976. Vol 10.

12. Perrot $\mathrm{M}$ et al. História da vida privada: da Revolução Francesa à Primeira Guerra. SP: Editora Schwarcz; 1995. Vol 4.

13. Deleuze G. Conversações. Rio de Janeiro: Ed. 34; 1992.

14. Menezes JEX. Usos foucaultianos da categoria familiar. In: Jacquet C, Costa LF, organizadores. Família em mudança. SP: Companhia Ilimitada; 2004. p. 291-310.

15. Giddens A. A transformação da intimidade. São Paulo: UNESP; 2000.

16. Brasil. Lei no 8.069 , de 13 de julho de 1990. Dispõe sobre o Estatuto da Criança e do Adolescente e dá outras providências [Acesso em 20 fev 2006]. Diário Oficial da União. 16 de jul 1990: 13563. Disponível em: http:// www.planalto.gov.br/CCIVIL/LEIS/L8069.htm

17. Petrini CP. A relação nupcial no contexto das mudanças familiares. In: Jacquet C, Costa LF, organizadores. Família em mudança. SP: Companhia Ilimitada; 2004. p.15-34.

18. Cecconello AM, Koller SH. Inserção ecológica na comunidade: uma proposta metodológica para estudo de famílias em situação de risco. In: Koller SH, organizador. Ecologia do desenvolvimento humano: pesquisa e intervenção no Brasil. São Paulo: Casa do Psicólogo; 2004. p. 267-291.

Recebido em: 14/04/2007 Modificado em: 31/05/2007 Aprovado em: 05/06/2007 